\title{
OS ELEMENTOS DIDÁTICO-GEOGRÁFICOS NO PROCESSO DE AÇÃO CONSCIENTE DOS PROFESSORES DE GEOGRAFIA
}

\author{
Ana Claudia Ramos Sacramento ${ }^{1}$ \\ Universidade do Estado do Rio de Janeiro
}

\begin{abstract}
Resumo:
A mediação do conhecimento geográfico escolar está associada a dois pontos importantes: ao conhecimento das ciências: geográfica e da educação, pois na articulação desses dois saberes, pode-se dizer que se desenvolve o trabalho docente em sala de aula. Então, pensar os elementos didático-geográficos dos professores é analisar alguns pontos que caracterizam a importância de ensinar Geografia, que não está somente na parte técnica em si, mas em tudo que permeia a construção do conhecimento. O objetivo deste artigo é dialogar a respeito dos elementos que fazem parte do processo de construção da aula desenvolvido na discussão realizada durante a pesquisa sobre consciência e mediação dos conhecimentos como parte da tese de doutoramento.
\end{abstract}

Palavras-chave: Mediação, didática, ensino de geografia.

\section{Resumen:}

La mediación del conocimiento geográfico escolar está asociada a dos puntos importantes: al conocimiento de las ciencias: geográfica e de la educación, pues la articulación de esos dos saberes desarrolla el trabajo del profesorado en la aula. Por el tanto, pensar los elementos didáctico y geográficos son algunos puntos que caracterizan la pertinencia de enseñar geografia, no solo en la parte técnica, pero en todo que está en la construcción del conocimiento. El proposito del artículo es hablar de los elementos que forman parte del processo del construcción de la aula desarrollado en la discussión de la investigación de consciencia y la mediación de los conocimientos como parte de la tesis doctoral.

Palabras Clave: Mediación, didáctica, enseñanza de geografía.

\footnotetext{
${ }^{1}$ anaclaudia.sacramento@hotmail.com
} 


\section{INTRODUÇÃO}

$\mathrm{O}$ ato consciente dos professores no seu processo produtivo - materialização da sua aula - se dá ao agir sobre algo que é necessário para que este tome consciência do seu fazer pedagógico. Marx e Engels ( $\mathrm{s} / \mathrm{d}$ ) caracterizam que toda consciência tem uma necessidade sobre o desenvolvimento de uma atividade produtiva, isto quer dizer, que ao pensar no trabalho docente, $\mathrm{o}$ ato consciente na sala de aula objetiva o ensino, sendo parte do ofício do que é ser professor. $\mathrm{O}$ ato consciente acontece devido a sua capacidade de reflexão sobre determinados aspectos do seu trabalho, de acordo com os seus conhecimentos e com os materiais que tem consigo.

$\mathrm{O}$ que significa dizer que a intencionalidade está no fato de os mesmos construírem elementos didático-pedagógicos para mediar os conhecimentos da leitura do mundo que está impregnado pelos fenômenos, da ação da sociedade e da organização espacial, materializada nas diversas paisagens, ordenadas territorialmente. $\mathrm{O}$ ato consciente se materializa na mediação que se constrói para o processo do ensinar- no caso - o geográfico. Definindo a Geografia como um conjunto de fenômenos geográficos que estão localizados no espaço, no qual o homem modifica sua atuação sobre estes fenômenos e sobre o meio em que vive, o propósito do aprendizado desta disciplina se refere a permitir com que o aluno busque elementos para compreensão sobre seu espaço vivido, tendo como referencial, a reflexão a cerca das transformações realizadas nestes espaços.

Desta forma, mediar o conhecimento geográfico significa construir com o outro o conhecimento daquilo que é próprio da geografia escolar, o processo de conhecimento significativo se caracteriza em transmitir para o outro, o próprio conhecimento e as experiências, diferenciando-se a partir da consciência da práxis sobre a atividade de organizar o ensinar, para que haja uma aprendizagem dos conceitos geográficos que implicam na importância de saber ler, interpretar, nos orientar, saber nos localizar em diferentes lugares ou onde se localizam os objetos no espaço. Segundo Moreira (2008a), a geografia é uma forma de leitura do mundo. Por isso, é necessário que exista uma lógica sobre o pensar os fenômenos para se desvencilhar do senso comum.

Desta maneira, o ponto de vista para se estudar a geografia: olhando o espaço, olhando em volta, percebendo o que existe, sabendo analisar as paisagens como o momento instantâneo de uma história que vai acontecendo. Essa é a leitura do mundo da 
vida, mas que não se esgota metodologicamente nas características de uma geografia viva e atual. (CALLAI, 2006)

Destaca-se as leituras dos autores Libâneo (2011, 2009), Bernardes e Moura (2009) e Assis Gomes (2002), sobre a questão do professor mediador em estabelecer relações próprias com o conhecimento.

Construir alguns pontos relevantes para se pensar sobre a Didática Contemporânea da Geografia, a partir de todo trabalho analisado durante a tese de doutoramento, pode-se trazer alguns fundamentos necessários para se pensar o processo de consciência e mediação dos professores, por meio de diálogos entre professores e alunos; relações didáticas: o conhecimento geográfico-pedagógico; dos processos de ensino e de aprendizagem geográficos; dos recursos didáticos para o ensino da Geografia; a problematização e a resolução de problemas do cotidiano no ensino de Geografia; avaliações, a territorialidade dos professores como ato reflexivo das suas ações didáticas.

\section{MEDIAR O CONHECIMENTO GEOGRÁFICO: O QUE SIGNIFICA?}

A mediação é o processo de conhecimento significativo que se caracteriza em transmitir para o outro, o próprio conhecimento e as experiências, diferenciando-se a partir da consciência da práxis sobre a atividade de organizar o ensinar, para que haja uma aprendizagem efetiva.

O processo de ensino e de aprendizagem pode tornar-se dinamizado para os alunos, quando o professor conhece as suas necessidades, sabe como é a sua comunidade, as possibilidades da escola, trabalhando em prol das coisas no qual ele acredita ser importante para o conhecimento de seus alunos. Segundo Sacristán (2000, p. 193-194):

[...] a mediação do professor ressalta o papel influente que este tem e a importância de sua formação cultural e profissional... Estes não são meros adaptadores dos currículos, sem que, através das introduções por eles realizadas dentro do próprio processo de desenvolvimento do currículo, se convertem em mediadores entre a cultura exterior e a cultura pedagógica da escola. O professor é, por ele, um agente decisivo para que o currículo real seja o projeto cultural desenvolvido nas condições objetivas, tal como as 
representa, e abaixo do crivo dos processos subjetivos através dos que se estende na ação.

O autor argumenta que o professor é um mediador do conhecimento, e como tal, não pode ser considerado mero reprodutor, pois a concretização do processo curricular depende da sua ação dentro da escola para que sejam alcançados os objetivos propostos no projeto educativo. Eles possibilitam a mediação entre a cultura do mundo e a relação cultural na escola, formulando situações de transformação no agir que permitam a transposição do conhecimento para a realidade vivida sem esquecer os conteúdos universais da Geografia.

Segundo Bernardes e Moura (2009), a mediação transmite uma forma de organizar as idéias sobre as atividades a serem mediadas, para que o mediado consiga produzir seu próprio conhecimento a partir de um processo histórico e cultural. $\mathrm{O}$ professor, por meio de sua consciência, articula instrumentos que possibilitem o processo de comunicação e de articulação das disciplinares escolares, importantes para uma concepção de ensino significativo ao aluno. Sendo que a construção do saber geográfico requer articulações e mediações de conhecimentos didático-pedagógicos sobre o que é a Geografia e qual sua importância para o cotidiano do aluno.

Segundo Assis Gomes (2002, p. 77) ao estudar Feuerstein menciona que "o mediador transmite sua visão de mundo ao mediado para que ele possa estabelecer a sua própria visão". Esta visão é fundada por meio da formação que ele desenvolveu ao longo de sua atividade docente, de sua busca pelo conhecimento, pela produção do saber que ele constrói, e isso, se desenvolve pela consciência que envolve uma reflexão sobre o processo de produzir da sua atividade. Ao fazer isto, é ideal que o aluno compreenda o processo e consiga desenvolver seu ponto de vista sobre algo de maneira a construir de sua consciência sobre os fenômenos existentes no seu mundo. Seus conhecimentos didáticos permitem um "diálogo", uma "interação" mais efetiva entre o saber e aluno (mediado).

A mediação promove a interpelação da ciência escolar sobre o cotidiano e sobre o próprio conhecimento do aluno. O professor ao pensar sua profissão, precisa compreender que sua função vai muito além de uma reprodução de um determinado conteúdo, mas sim, uma busca de "construir" uma visão de mundo para que o mediado 
conheça os conceitos e os conteúdos de uma determinada disciplina e saiba transpor para o seu cotidiano.

Ao dar significado à mediação, Matias (2006) destaca que neste processo, o professor deve estabelecer sua intencionalidade e conhecer o processo de aprendizagem dos alunos, observando não apenas os aspectos cognitivos, mas também os sociais, afetivos, econômicos e culturais para a produção do conhecimento.

Neste processo é ressaltado que a apropriação, parte do processo de mediação e faz com que o indivíduo se aproprie de alguma coisa a partir da lógica do outro e se permite se reconstruir sobre um determinado objeto, assunto ou pessoa. Esta apropriação sobre algo a ser conhecido é uma forma de fazer com que os indivíduos desenvolvam um conhecimento sobre o outro ou sobre sua história.

\section{OS ELEMENTOS CARACTERICADOS DA MEDIAÇÃO GOEGRÁFICA ESCOLAR}

A mediação é de extrema importância, pois por meio dela, os fenômenos geográficos e todo o processo do conhecimento da Geografia Escolar estão orientadas para que o professor, através de uma consciência geográfica adquirida por ele no seu processo de formação, consiga trabalhar os elementos necessários para a construção do conhecimento geográfico escolar.

Ao mediar o conhecimento, ele constrói meios que possibilitem sua relação com o aluno, perpassando pelo conhecimento didático-pedagógico que este possui e sobre o próprio conhecimento sobre a ciência em questão - no caso com a geografia escolar, como destaca Libâneo (2011, p. 91):

O papel do professor, portanto, é o de planejar, selecionar e organizar os conteúdos, programar tarefas, criar condições de estudo dentro da classe, incentivar os alunos para o estudo, ou seja, o professor dirige as atividades de aprendizagem para os alunos a fim de que estes se tornem sujeitos ativos da própria aprendizagem.

Sendo assim, pensar a Didática como uma ciência que promove investigar e orientar a aprendizagem, requer principalmente dos professores, uma formação constante, uma reflexão das concepções teórico-práticas que envolvam o conhecimento das ações sociais e culturais na prática do cotidiano escolar. 


\section{a) Diálogos entre professores e alunos}

Os professores desenvolvem diferentes formas de dialogar com seus alunos. Esta é uma das relações mais significativas dentro da sala de aula, pois os alunos são o sujeito/objeto da relação dual de aprendizagem. Ensina-se para alguém e este ensinar deve possibilitar "caminhos" que auxiliem na produção do conhecimento. Os professores ao possibilitar que os alunos se expressem e participem de forma ativa durante as aulas, tornam as suas ações em um ato consciente, pois concebem que os alunos também dialoguem com eles.

Fazer isso é permitir que os docentes organizem seus saberes, na busca de uma aula mediada, ou seja, que no ato comunicativo eles consigam construir os conhecimentos geográficos de maneira que os alunos entendam e se organizem para transpor o conhecimento para a vida cotidiana. Aqui, a relação permite ser mantida a fim de que os professores e os alunos estabeleçam um contrato didático, no qual a percepção do saber seja no sentido de promover a aprendizagem significativa, mesmo que não seja só esse tipo de relação, mas pensando em outros fatores que fazem parte da aula. Segundo Libâneo (2007, p. 249)

A interação professor-alunos é um aspecto fundamental da organização da "situação didática, tendo em vista alcançar os objetivos do processo de ensino: a transmissão e a assimilação dos conhecimentos, habitados e habilidade". Entretanto, esse não é o único fator determinante da organização do ensino, razão pela qual ele precisa ser estudado em conjunto com outros fatores, principalmente a forma de aula (atividade individual, atividade coletiva, atividade de pequenos grupos, atividade fora de classe etc.).

Pensar em como se dialoga é traduzir como os professores se articulam nesse ato de falar. Que tipo de argumento eles precisam desenvolver para que os alunos consigam compreender os conteúdos geográficos. O professor deve ser aquele que exerce, na relação pedagógica de diversas práticas de atos comunicativos específicos da sua profissão: prelecionar, explicar, fazer perguntas, encorajar os alunos a falar. 
Sendo assim, os professores de Geografia precisam estabelecer diferentes formas de os alunos comentarem a respeito de as suas vivências sobre o cotidiano, para se sentirem à vontade de falar e de destacar fatos sobre os conteúdos expostos.

Afirma-se que os diálogos em Geografia podem ser organizados, a partir das concepções sobre os tipos de fenômenos geográficos territorializados, sobre as localizações dos objetos e da sociedade, ou também, sobre a forma de analisar a paisagem que os professores conhecem ou vivenciam. Assim como, mediar o conhecimento de maneira tradicional, de maneira construtivista, de maneira dialógica, depende de como os professores dominam os procedimentos didáticos e as formas que eles creem serem mais eficientes para organizar o conhecimento.

Considera-se que o ato de mediar os conhecimentos geográficos permite um diálogo que se concretiza a partir das relações comunicativas estabelecidas quando os professores se apropriam daquilo que seja importante para ensinar Geografia.

\section{b) Relações didáticas: o conhecimento geográfico-pedagógico}

Pensar o conhecimento é refletir sobre a relação entre o sujeito e o objeto a ser conhecido. Essas relações são estabelecidas a partir da necessidade do que se quer conhecer e de como esse conhecimento é organizado e comunicado. Ele se constrói a partir do momento em que se institui relações com os outros, com os meios e com as necessidades por meio do ato intencional, tanto sobre a construção do conhecimento como pelo processo de produção dos objetos.

Segundo Mello (2000), o processo de conhecimento se constitui no reflexo ativo da realidade, a partir da atividade do ser, caracterizado como intencional e transformador. É importante pensar qual seria o ato intencional dos professores de Geografia? Por que eles fazem parte dessa intencionalidade? Porque o agir faz parte do instinto humano e é a partir de como os professores buscam agir, é que eles constroem as aulas, pensando sobre como devem ensinar os conhecimentos. Um dos elementos dessa intencionalidade é como eles trabalham os conceitos e os conteúdos geográficos.

Sendo assim, os professores, ao conhecerem, que existem novas pesquisas sobre a Geografia Escolar e mesmo sobre as concepções didático-metodológicas poderiam trazer outras possibilidades de ensinar Geografia, desvinculando de ações mais tradicionais. Por isso, a necessidade de entender a Educação Geográfica, como as 
mudanças e as permanências dos fenômenos materializados no espaço, fazendo com que os alunos construam seu próprio conhecimento e consigam transpor esse conhecimento para a realidade. E ele tem um caráter próprio, pois segundo Pizzinato (2007, p. 111)

[...] la Geografía escolar hace referencia a un proceso de toma de decisiones conciente por parte del docente, en el cual su prioridad es el saber escolar, producto de la relación entre los elementos de la disciplina y aquellos que son objeto de enseñanza, es decir, que en la escuela no debe circular el "saber sabio", sino la transformación didáctica de este por la acción mediadora del maestro.

A autora corrobora as nossas discussões sobre a consciência dos professores. Ela destaca que os professores precisam tomar decisões de como ensinar e buscar trazer elementos para que possam mediar os conhecimentos geográficos. Então, $\mathrm{o}$ ato consciente dos professores é dar significado aos conceitos e os conteúdos, para fazer com que os alunos tenham consciência sobre o raciocínio espacial e considerar que os objetos e os fenômenos que estão a sua volta acontecem, devido às relações físicas, naturais e humanas no tempo e no espaço.

Trabalhar o conteúdo na escola é o meio para desenvolver a capacidade dos alunos na compreensão de sua realidade, por intermédio de um sistema organizado, com valores científicos e orientadores que permitirá a ele construir sua capacidade de ler o mundo a sua volta, sua relação entre o próximo/distante e compreender historicamente as suas transformações.

A abordagem de conteúdos trará uma visão mais aberta da importância de cada um em sala de aula, e como os professores desenvolverão o tema a abordar. Mas, ao pensar sobre isto, cada professor deve escolher como interpretará a realidade e quais os elementos necessários para a aprendizagem de seu aluno. Os conteúdos na geografia escolar precisam possibilitar a resolução de problemas sociais relevantes, como pensar a cidade, os problemas sócio-ambientais, a ocupação desordenada dos relevos entre outros.

Assim como, Filho (2010, p. 111) comenta que o desenvolvimento do pensamento espacial voltado para a formação integral da pessoa, cumprindo tanto esse papel de contribuir para a educação escolar formal, como de explicitar as contradições do movimento da sociedade na produção do seu espaço. 
Contudo, outro aspecto importante da relação didática é a mediação dos conhecimentos didático-pedagógicos sobre conceitos e conteúdos. Ao pensar sobre a importância desses conhecimentos, Gasparin destaca que:

O processo pedagógico deve possibilitar aos educandos, através do processo de abstração, a compreensão da essência dos conteúdos a serem estudados, a fim de que sejam estabelecidas as ligações internas específicas desses conteúdos com a realidade global, com a total da prática social e história. Este é o caminho por meio do qual os educandos passam do conhecimento empírico ao conhecimento teórico-científico, desvelando os elementos essenciais da prática imediata do conteúdo e situando-o no contexto da totalidade social. (GASPARIN, 2002, p. 6)

Os conhecimentos didático-pedagógicos são relevantes para se pensar os caminhos, os meios, as formas de como estabelecer a relação entre o conhecimento e os alunos. As ações didáticas permitem que os professores escolham, de acordo com suas realidades, quais serão as condições para orientar a construção do conhecimento dos fenômenos geográficos. Desta maneira, a necessidade de entender as principais concepções pedagógicas e quais são suas influências para o ensinar e o aprender, pois os professores confeccionam estratégias ou atividades de aprendizagem específicas sobre o ensino de Geografia que chegará a fazer com que os alunos aprendam fazer a leitura espacial sobre os fenômenos localizados na superfície da terra.

\section{c) O processo de ensino e de aprendizagem geográfico}

Os atos de ensinar são as atividades da consciência da ação docente ao intervir e mediar os conhecimentos geográficos, com a intenção de contribuir para que os alunos conduzam sua vida sem alienação, tendo ciência dos processos, fatos e fenômenos que acontecem em seu cotidiano. Nesse âmbito, o professor deve pensar sua prática para organizar uma didática que permita o desenvolvimento de conteúdos críticos, promovendo ações no cotidiano do aluno.

Ensinar, de modo geral, significa proporcionar ao aluno, tanto o acesso ao conhecimento historicamente produzido, quanto a uma atitude reflexiva ante a realidade 
vivida. Trata-se da formação dinâmica e orgânica, pela qual o aluno adquire determinadas aptidões intelectuais que se traduzem em habilidade retórica e capacidade de argumentação, concretizadas no esforço, em problematizar, desvelar os supostos, duvidar de fatos e razões apresentados como evidentes, despertar a força da negação, enfim, realizar o trabalho de crítica.

Pode-se destacar que os autores como Delgado Carvalho (1925), Proença (s/d), Lago (1956), Resende (1986) e outros, sugerem em seus trabalhos que o professor diversifique o seu modo de trabalhar, trazendo novas técnicas, novas dinâmicas e atividades que possam relacionar à construção do conhecimento geográfico.

Ensinar geografia é permitir que os alunos compreendam as transformações dos fenômenos geográficos que interferem no modo de vida não só do aluno, mas da sociedade na qual ele vive. Para tanto, entender essa dinâmica é analisar e compreender como esses fenômenos interagem no espaço. Para isso, as ações didáticas dos professores estão relacionadas a entender como fazer com que os alunos aprendam. Meirieu (1998, p. 51) destaca que os alunos, ao construir o conhecimento, precisam estar atentos, ler e escutar, receber informações que sejam relevantes, isto quer dizer que, os professores precisam construir e compreendam os signos e os fenômenos e desenvolver atividades de aprendizagem que fazem os alunos a organizarem a parte cognitiva. Essas ações precisam ter a intencionalidade de estimular o processo de leitura e de escrita sobre os conhecimentos que são construídos ao longo das aulas. Sendo assim, a aprendizagem se concretiza a partir do momento em que os alunos são colocados em situações específicas e consigam transpor esses conhecimentos científicos para o cotidiano.

A questão da aprendizagem está vinculada com as ações que os professores desenvolvem em sala de aula, sendo entendida como um processo de construção do espaço em suas múltiplas funcionais.

A aprendizagem deve ser construída para pensar os principais aspectos que os alunos devem conhecer sobre os saberes geográficos. Que eles tenham domínio e saibam articular esse conhecimento, na compreensão dos espaços socialmente construídos pela sociedade que se utiliza de recursos da natureza. Para isso, a aprendizagem deve ser um processo de interação entre o aluno e o saber, na qual ele deve ser conduzido a transpor seu conhecimento, se apropriando dos conhecimentos que são propostos a ele. 
A forma como os alunos aprendem depende de como os professores se comunicam, organizam e elaboram atividades, de acordo com as características específicas das séries a serem ensinadas, para fazer com que os alunos compreendam conscientemente as mudanças espaciais.

\section{d) Os recursos didáticos para o ensino da Geografia}

Historicamente, pode-se dizer que o uso de materiais diversificados nas salas de aula, sempre foi uma referência na discussão de diferentes propostas de ensino, sendo propiciada pelas novas políticas educacionais no âmbito curricular, que se alicerçam em um discurso de reforma educacional, o qual passou a ser sinônimo de renovação pedagógica, progresso e mudança. (FISCARELLI, 2008)

Os materiais didáticos têm como função principal, auxiliar o professor, em um primeiro momento, e também o aluno, em outro momento, na busca dos elementos necessários para o desenvolvimento do processo de ensino e aprendizagem, no saber e na aplicação prática. Eles são recursos variados que possibilitam múltiplas abordagens para um mesmo assunto/conteúdo/propósito, fazendo com que o professor desenvolva sua didática. Os referidos recursos permitem uma flexibilidade no processo educativo, possibilitando atingir os objetivos propostos. Materiais esses, que os professores precisam dominar para saber utilizá-los no planejamento da aula.

Pode-se dizer que dependendo dos professores, vários recursos podem ser utilizados, o que dependerá do momento mais propício para uso, segundo escolha dos docentes. Destaca-se que os meios/recursos "próprios" da Geografia são os mapas, os globos, os Atlas e as imagens, pois é do conhecimento de todos que a disciplina tem a priori, a localização como um dos elementos de estudo. Isto não quer dizer que não se utiliza de outros meios como: jogos, filmes, livros, e outros para pensar o desenvolvimento da aula. Segundo Castellar (2005a, p. 222)

Os mapas e as imagens presentes nas aulas são procedimentos, ou seja, estratégias de aprendizagem que possibilitam aos alunos trazer para a discussão o conhecimento prévio e ao mesmo tempo mobilizam habilidades mentais (classificar, analisar, relacionar, sintetizar...) e estimulam a percepção, bem como a observação e a comparação das influências culturais existentes nos diferentes 
lugares. Permitem ainda que os alunos entendam os mapas como construções sociais que transmitem idéias e conceitos sobre o mundo, apesar da pretendida neutralidade e objetividade que os meios técnicos utilizam para confeccioná-los.

Autores como Delgado de Carvalho (1925), Proença (s/d), Lago (1956), destacam a importância dos recursos didáticos para o ensino de Geografia, criando situações que permitam trabalhar com os materiais que correspondem a uma aprendizagem significativa para este ensino. Em suas metodologias de ensino, eles mostram como utilizar os recursos com o objetivo de mediar os conhecimentos.

Ressalta-se que os professores, em sua prática pedagógica, devem conscientizarse do papel que esses meios/recursos têm em sala de aula. Contudo, para a apropriação do uso dessas linguagens, com seus códigos e suas formas de representação, são necessárias determinadas estratégias de aprendizagem que desenvolvam nos alunos o raciocínio lógico e a compreensão dos conceitos e conteúdos necessários para a construção do seu saber.

Para promover a ampliação do conhecimento dos alunos a respeito de temas cuja relevância é de inquestionável valor para a sociedade atual, os materiais didáticos são fundamentais no trabalho do professor.

O trabalho do professor de Geografia precisa ser ancorado por uma ampla variedade de materiais que possibilitem planejar boas situações didáticas, buscando essa articulação ampla de conteúdos que acabamos de citar. Criar situações que permitam que os alunos possam progredir em suas aprendizagens sobre o mundo e sua própria vida, nas diferentes paisagens que compõem esse mundo.

\section{e) A problematização e a resolução de problemas do cotidiano no ensino de Geografia}

No ensino de Geografia é comum utilizar o cotidiano como um elemento para a mediação dos conceitos e dos conteúdos a serem ensinados, assim como o papel da problematização, para organizar e auxiliar nas novas concepções de ensino e aprendizagem que são vinculados à forma da Educação Geográfica. 
O cotidiano é enriquecido de objetos práticos e teóricos que fornecem ao homem várias formas de pensar e agir de acordo com sua experiência. Nesta modificação o relacionamento do homem busca compreender a transformação deste mundo que ele experimenta nas relações do seu "eu" com os outros e com seu espaço vivido.

Desde Delgado de Carvalho (1925), o cotidiano é destacado como um elemento importante no processo de aprendizagem do aluno, pois os professores ao pensarem os conteúdos nessa perspectiva, promovem uma aprendizagem significativa para o aluno. É evidente que só isso não promove a compreensão dos alunos, se caso os professores não usem metodologias que os façam refletir sobre as concepções de mundo que estão a sua volta.

A este respeito, Cavalcanti (1998, p. 129) também destaca a importância de se relacionar o cotidiano do aluno e o aprendizado dos conteúdos geográficos. Conteúdos esses, vinculados aos fenômenos geográficos ou aos lugares que interferem na vida dos alunos. Ainda segundo a autora: "A Geografia na escola deve estar, então, voltada para o estudo de conhecimentos cotidianos trazidos pelos alunos e para seu confronto com o saber sistematizado que estrutura o raciocínio geográfico".

O ensino de Geografia tem a função de transformar o modo de pensar sobre a organização do espaço, e principalmente, conscientizar esses alunos como seres espaciais. Para tanto, não basta somente destacar o cotidiano, mas saber trabalhar com ele, já que esses conhecimentos estão incorporados nos elementos espacializados.

À luz dos pensamentos de Lefébvre (1991), o cotidiano se modifica e se torna um elemento importante para que os alunos conheçam seu espaço vivido, uma vez que é no cotidiano que se faz presente à vivência do homem, o uso do território, as dinâmicas sócio-culturais e político-econômicas, como forma de transformação da realidade.

Para se trabalhar com o cotidiano é importante que os professores saibam criar situações em que os alunos sejam colocados em interação com a realidade, segundo Gasparin (2002, p. 35), o método de problematização é utilizado sempre que os temas estejam relacionados à vida em sociedade.

[...] a problematização tem como finalidade selecionar as principais interrogações levantadas na prática social a respeito de determinado conteúdo. Essas questões, em consonância com os objetivos de 
ensino, orientam todo o trabalho a ser desenvolvido pelo professor e pelos alunos.

Quando os professores buscam ensinar a partir de um problema, eles precisam desenvolver atividades, com perguntas problematizadoras sobre a realidade. As perguntas feitas não podem ser prontas, mas orientadas para que os alunos possam transpor o conhecimento.

A metodologia de resolução de problemas estudada por Moraes (2010, p. 74) é caracterizada a partir de estratégias didáticas necessárias para formulação de perguntas, que devem ser vistas não como um final, mas como um processo, em toda a etapa dessa aprendizagem. Segundo a autora, o uso dessa metodologia possibilita o aluno a desenvolver:

- hipóteses diante do problema; b) trabalho com diferentes recursos; c) confronto com diferentes hipóteses; d) busca de soluções que respondam aos questionamentos; e) mudança de postura sobre o aprendizado.

Pensar didaticamente dessa forma é perceber a importância que os alunos têm nesse contexto. É permitir que a aprendizagem seja construída pelos discentes, a partir do momento em que os professores construam ao longo do seu processo didático, formas que estimulem o conhecimento do espaço transformado no presente. Desta maneira, pensar a resolução de problemas, pode ser adequado para organizar as aulas e a vislumbrar a possibilidade de ações concretas sobre as experiências vividas pelos alunos. Segundo Moraes (2010, p. 88)

Em relação aos saberes geográficos, é muito importante pensar em práticas que estimulem o questionamento sobre um determinado fenômeno. Nesse processo, o aluno terá a oportunidade de lidar com a ciência com o mesmo envolvimento que o trabalho de um cientista requer: a curiosidade poderá ser suscitada, o conhecimento poderá ser problematizado, haverá a possibilidade de ir além do que se conhece, o aluno aprenderá a argumentar de acordo com os resultados que for obtendo, entre outras aproximações possíveis. 
Fazer essas relações é romper com os métodos tradicionais que estão, em diversos momentos, enraizados nas aulas. O rompimento pode contribuir para o conhecimento didático-pedagógico e para as concepções de novas metodologias que estão sendo teorizadas.

\section{f) A avaliação para a Geografia}

A avaliação é o processo pelo qual se cria situações para buscar dados sobre o ensino e a aprendizagem do aluno, auxiliando os professores na análise do andamento dos seus trabalhos. A partir dos resultados, os docentes podem investigar os avanços ou não dos conhecimentos aprendidos pelos alunos durante as aulas.

Para Luckesi (1995, p.33), a avaliação “é um julgamento de valor sobre manifestações relevantes da realidade, tendo em vista uma tomada de decisão”. Isto quer dizer, que os professores constroem as atividades pensadas, levando em conta, o tipo de conclusão que os alunos devem chegar, a partir de atividades avaliativas de aprendizagem.

O planejamento da avaliação precisa ser pensado como um processo e não como um fim da aprendizagem, pois as ações dos resultados devem ser refletidas para que os professores saibam como desenvolver as aulas. Notamos que este tema é extremamente importante, não só o aluno está sendo avaliado, como o professor e a própria escola. Fazse necessário, refletir para que se alcance o objetivo real da avaliação.

Cordeiro (2007) comenta que este processo é organizado de duas maneiras: como seleção ou como atividades voltadas ao ensino e ao aprendizado. É importante destacar que as duas são válidas, dependendo da necessidade do professor ou da instituição de ensino, em querer realizar as atividades. Contudo, para constatar a aprendizagem do aluno, o uso da avaliação qualitativa se configura em um instrumento importante, uma vez que está focada no processo de construção de conhecimento dos alunos.

Desta maneira, pensamos o que significa avaliar em Geografia, qual é o sentido que a avaliação deve ter para esta disciplina. Castellar e Moraes (2010, p. 146) argumentam que:

o objetivo principal do professor é auxiliar o aluno a organizar seu pensamento e a formar o pensamento científico. Essa organização do pensamento e formação científica é feita fundamentalmente, por meio de operações mentais que o professor incentiva em seus alunos. 
Operar mentalmente é agir sobre o pensamento, é dar sentido ao conhecimento que se está adquirindo, é tornar o aluno capaz de reconstruir por si só aquilo que aprendeu.

A avaliação, então, é o ato consciente dos professores em organizar e preparar atividades de aprendizagem que envolvam os alunos, as quais tenham sentido e promovam a reflexão do aluno sobre os conteúdos e os conceitos trabalhados. Esse ato se constrói, com as concepções teórico-práticas dos professores, ao entenderem o que é importante à percepção dos alunos.

Sendo assim, a avaliação em Geografia precisa refletir as ações dos fenômenos geográficos, a orientação e a localização, os conceitos pertinentes à ciência geográfica e as mudanças e permanências existentes nas paisagens, dentre outros.

Essas ações precisam estar calcadas em conceitos geográficos que estimulem a construção de possibilidades de compreender a realidade vivida.

Todas as atividades criadas ou utilizadas que caracterizaram um processo de construção da aprendizagem foram relacionadas à linguagem cartográfica; em outros momentos, às diferentes linguagens, principalmente as imagens e os filmes/documentários.

\section{CONSIDERAÇÕES FINAIS:}

A discussão sobre o processo de mediação é uma das chaves para se refletir da consciência sobre o ensinar, pois o ato consciente está no fato de um ser agir com o outro, sobre a relação com as coisas que estão à sua volta e a necessidade sobre a materialidade concreta, que se dá por meio do processo de ensino e de aprendizagem de determinados conteúdos e conceitos específicos - que se materializa na aula de Geografia. Além disso, a forma como mediam os conhecimentos, está intimamente ligada à tomada de consciência dos professores, referente à utilização de novas abordagens de ensino ligadas a própria disciplina Geografia..

Desta forma, na pesquisa de doutorado, pode-se analisar a importância dos docentes compreenderem os principais elementos que caracterizam o ato de mediação do conhecimento, como forma do ato de trabalho que eles desenvolvem todos os dias na sala de aula. Esta reflexão promove um diálogo sobre o papel do professor na construção e produção do conhecimento geográfico. 


\section{REFERÊNCIAS}

ASSIS G., C. M. (2002). Experiência da aprendizagem mediada. In: Feuerstein e a Construção Mediada do Conhecimento. Porto Alegre: Artmed Editora. p 71-108.

BERNARDES, M. E. M.; MOURA, M. O. de. (2009) Mediações simbólicas na atividade pedagógica. In: Educação e Pesquisa. São Paulo, v 35, n. 3, set/dez. p. 463-478.

CARVALHO, D. de. (1925). Methodologia do Ensino Geographico - Introdução aos Estudos de Geographia Moderna. Tomo I, Petrópolis, RJ: Typographia das Vozes.

CASTELlAR, S.. (org) (2005a). Educação Geográfica: a psicogenética e o conhecimento escolar. In: Educação Geográfica e as Teorias de Aprendizagens. Campinas- SP: Cadernos Cedes., col 25, $\mathrm{n}^{\circ}$ 66, .maio/ago. p. 209-225.

CASTEllaR, S.; MORAES, J. (2010). Ensino de Geografia. Porto Alegre: Thompson.

CAVALCANTI, L. de S. (1998). Geografia, Escola e Construção de conhecimentos. São Paulo: Papirus.

CORDEIRO, J. F. P. (2007). Didática. São Paulo: Contexto.

FILHO, M. M. de S. (2010). A educação geográfica escolar: conteúdos e referências docentes. Tese de Doutorado. São Paulo: Pós-graduação em Geografia Humana- FFLCH/ Departamento de Geografia-USP.

FISCARELLI, R. B. de O. (2008). Material didático: discursos e saberes. Belo Horizonte: Junqueira \& Marin Editora.

GASPARIN. J. L. Uma didática para a pedagogia histórico-crítica. (2002). São Paulo: Autores Associados.

LAGO, P. F. de A. (1956). Didática Especial de Geografia. Ministério da Educação e Cultura.

LEFEBVRE, H. (1991). A vida cotidiana do mundo moderno. São Paulo: Ática.

LIBÂNEO, J. C. (2011). Didática e trabalho docente: a mediação didática do professor nas aulas. 
In: LIBÂNEO, J. C.; SUANNO, M. V.R.; LIMONTA, S. V. (Org.). Concepções e práticas de ensino num mundo em mudança: diferentes olhares para a didática. Goiânia (GO): CEPED/Editora da PUC GOIAS, v. 1, p. 85-100.

LIBÂNEO, J. C. (2007). Didática. $27^{\mathrm{a}}$ ed. São Paulo: Cortez.

LUCKESI, C. C. (1995). Avaliação da aprendizagem escolar. $1^{a}$ ed. São Paulo: Cortez.

MATIAS, V. R. da S. (2006). As relações entre Geografia, mediação pedagógica e desenvolvimento cognitivo: contribuições para a prática de ensino em Geografia. In: Caminhos de Geografia.

Uberlândia: Instituto de Geografia - Programa de Pós-graduação em Geografia da Universidade Federal de Uberlândia. no 24 (17) fev p. .250 $-264$.

Disponível em: www.caminhosdegeografia.ig.ufu.br/viewarticle.php?id=169 acesso em 24 de janeiro de 2010.

MARX, K.; ENGELS, A Ideologia Alemã.

Disponível em:

http://www.dominiopublico.gov.br/pesquisa/DetalheObraForm.do?select_action $=\&$ co_obra=2233 acessado em 10.07.2010

MELLO, S. A. (2000). Linguagem, consciência e alienação: o óbvio como obstáculo ao desenvolvimento da consciência crítica. Marília: UNESPMarília-Publicações.

MORAES, J. V. de. (2010). A alfabetização científica, a resolução de problemas e o exercício da cidadania: uma proposta para o ensino da Geografia. Tese de doutorado. São Paulo: Faculdade de Educação-USP.

PIZZINATO, L. A. R. (2007). Una geografía escolar (in)visible. Desarollo del pensamiento espacial desde la construcción de conceptos geográficos. Bogotá: Universidad Distrital Francisco José de Caldas.

PROENÇA. A. F. Como se ensina Geographia. Biblioteca de Educação organizada pelo Dr. Lourenço Filho. São Paulo: Comp. Melhoramentos de São Paulo. s/d. 
OS ELEMENTOS DIDÁTICO-GEOGRÁFICOS NO PROCESSO DE AÇÃO CONSCIENTE DOS PROFESSORES DE GEOGRAFIA

Ana Claudia Ramos Sacramento

Revista de Didácticas Específicas, nº 12, PP. 98-116

SACRISTÁN, J. G. (2000). O currículo: uma reflexão sobre a prática. $3^{\mathrm{a}}$ ed. Porto Alegre: Artmed. 